\title{
Light Levels for Parking Facilities Based on Empirical Evaluation of Visual Performance and User Perceptions
}

Rajaram Bhagavathula

Virginia Tech Transportation Institute

3500 Transportation Research Plaza, Blacksburg, VA 24061

Phone: (540) 231-5209; Fax: (540) 231-1555; Email: Rbhagavathula@vtti.vt.edu

Ronald B. Gibbons

Virginia Tech Transportation Institute

3500 Transportation Research Plaza, Blacksburg, VA 24061

Phone: (540) 231-1581; Fax: (540) 231-1555; Email: Rgibbons@vtti.vt.edu

Keywords: Light Levels, Parking Facilities, Parking Garages, Parking Lots, Visibility, Visual Performance 


\begin{abstract}
Light levels recommended for parking facilities should be backed by empirical research that accounts for all users. In the current study, pedestrians' and drivers' visual performance and their perceptions of safety, comfort, and visibility were evaluated at a parking garage and at parking lots with asphalt and concrete pavements under three light source types (high pressure sodium luminaire, $3000 \mathrm{~K}$ light-emitting diode [LED] luminaire, and $5000 \mathrm{~K}$ LED luminaire) and at multiple light levels. Visual performance involved facial and hand recognition, wheel stop detection, detection of a side-facing pedestrian, and detection of a vehicle backing up from a parking spot. Perceptions of safety, comfort, and visibility were assessed by means of a questionnaire. Results showed that in the parking garage, an increase in light level beyond 10 lux of average horizontal pavement illuminance did not result in a statistically significant increase in visual performance or perceptions of safety, comfort, and visibility. For parking lots of asphalt and concrete pavements, this plateauing was observed at the 2 lux light level. No statistical differences were observed between the light source types for the visual performance tasks, but the perceptions of safety, comfort, and visibility were highest for the 5000 K LED luminaires.
\end{abstract}

\title{
1 Introduction
}

Adding lighting to an environment increases safety by increasing the amount of available visual information (Gibbons and others 2014). However, the increase in visibility achieved by increasing illuminance usually plateaus (Adrian 1989; Bhagavathula 2016; Bhagavathula and others 2018; Rea and Ouellette 1991). Determining this plateau level will help lighting designers attain optimal visibility in parking lots without energy waste, glare, or light trespass. Increasing illuminance beyond this plateau also wastes energy and may also increase discomfort and disability glare. To determine parking lot illuminance levels that increase visibility along with the comfort, safety, and visibility perception of parking lot users while conserving energy and reducing glare, it is important to determine realistic tasks that account for all parking lot users and their interactions. 
In the latest version of the Illuminating Engineering Society (IES) Recommended Practice (RP) - 20 document, the light levels recommended for parking lots (RP-20-14) are significantly higher than those in the previous version (RP-20-98). Some recommended illuminance levels are twice as high for parking lots with asphalt pavement and five times as high for parking lots with concrete pavement (Table 1). The higher horizontal illuminance recommendations in RP-20-14 were likely based on a single critical task: detection of a non-painted concrete wheel stop on a concrete pavement. However, this critical task only accounts for pedestrians' detection of trip hazards and ignores other interactions between vehicles and pedestrians. Moreover, detecting a wheel stop with similar texture and color to the surface on which it is placed requires a high luminance contrast, which could be obtained by increasing pavement illuminance in parking lots (Adrian 1989; Pretto and Chatziastros 2006).

Table 1. Increase in recommended maintained horizontal illuminance from RP-20-98 to RP-2014.

\begin{tabular}{|l|l|l|l|l|}
\hline & Pavement Type & RP-20-98 & RP-20-14 & Increase in Illuminance \\
\hline Basic & All & 2 lux & & \\
\hline Enhanced & All & 5 lux & & \\
\hline Pre-curfew & Asphalt & & 5 lux & 2.5 times \\
\cline { 2 - 5 } & Concrete & & 10 lux & 5 times \\
\hline \multirow{2}{*}{ Post-curfew } & Asphalt & & 2 lux & \\
\cline { 2 - 5 } & Concrete & & 2 lux & \\
\hline
\end{tabular}

As they are the primary users of parking facilities, pedestrians and drivers should both be involved in the critical tasks used to determine the lighting requirements of parking structures. Three major tasks involve both types of users and should be taken into consideration when developing lighting requirements:

1. Driver-to-pedestrian/other driver interactions; 
2. Pedestrian and driver obstacle detection and navigation; and

3. Pedestrian and driver perceptions of comfort, safety, and visibility.

In parking lots and garages, two sources of light affect visibility: fixed parking lot/garage lighting and light from vehicle headlamps. Of these, only the fixed parking lot/garage lighting can be controlled by the lighting designer. Research has shown that increased light level is associated with an increase in visual performance (foveal and peripheral) (Bhagavathula 2016; Bhagavathula and others 2018; Boyce 1973; Eloholma and others 2006; Gibbons and others 2015; Illuminating Engineering Society of North America 2000; Terry and Gibbons 2015). For pedestrians to safely navigate parking lots/garages, they should be able to successfully detect such pavement obstacles (e.g., wheel stops, curbs, and raised pedestrian walkways) that could cause them to trip and fall (Caminada and Van Bommel 1984). Further, eye-tracking studies have shown that scanning for a trip hazard is higher at night (Fotios and others 2015a). Research into obstacle detection has shown that increased illuminance aids in the detection of obstacles at lower heights, while the lamp spectrum does not affect obstacle detection at illuminance levels over 2 lux (Fotios and Cheal 2009).

In addition to increasing pedestrians’ visual performance, parking lot/garage lighting should increase their perceptions of comfort and safety at night, which is commonly assessed using facial recognition. Although a vertical illuminance between 4 and 10 lux has been shown to increase facial detection and recognition (Boyce and Rea 1990), there is no clear agreement on the effect of the lamp spectrum on facial recognition (Knight 2010; Rea and others 2009). Studies have also indicated a relationship between pedestrians’ perception of a location’s safety and its brightness (Boyce and others 2000). 
Sources with higher correlated color temperature (CCT) such as light-emitting diodes (LEDs) also affect perceptions of safety in parking lots. The replacement of metal halide lamps with LEDs in a California supermarket enhanced the perception of safety and improved the parking lot's appearance according to the employees (Johnson and others 2009). Knight (2010) also found that replacing metal halide lamps with LEDs enhanced perceptions of brightness, safety, and comfort. Lighting uniformity (maximum to minimum ratios) also affect the perception of parking lot safety. Narendran and others (2016) found that more uniform lighting is perceived to be safer, even at lower average illuminance, and recommended an average illuminance of 9 lux at 3:1 uniformity for parking lots with LED luminaires.

Recommending light levels that increase visual performance along with perceptions of safety, comfort, and visibility for all users in parking lots and garages calls for empirical research that evaluates visibility in parking facilities based on the critical tasks of both drivers and pedestrians. Existing research is predominantly conducted from the pedestrian's point of view, while visibility evaluations of parking facilities from the driver's point of view are lacking. It is important to determine if there are differences between driver and pedestrian-required light levels. There is also a need to understand whether the same light levels can ensure optimal visibility in both parking lots and garages. Empirical evaluations should also determine the optimal light at which the objective and subjective measures of visibility plateau and assess the visibility of solid-state lighting systems like LEDs in parking facilities so that appropriate recommendations for light source types can be made. Finally, it is imperative that the needed evaluations be conducted in realistic environments.

This study aimed to understand the effects of lighting source types and levels on the visual 
performances of pedestrians and drivers during critical visual tasks in parking lots and garages. The results of this study will inform lighting recommendations for parking facilities in IES RP20, Lighting for Parking Facilities.

\section{Methods}

\subsection{Experimental Design}

A repeated measures experimental design was utilized to analyze the effects of light source type and light level on objective measures of visual performance and subjective ratings of safety, comfort, and visibility in parking garages and parking lots. Three real parking facilities were selected for evaluation: one parking garage and two parking lots (one with asphalt pavement and the other with concrete pavement on the roof of a parking garage). The selection of real parking facilities serves three purposes. First, the evaluation results will have real-world implications. Second, the facilities selected will account for different pavement types encountered in parking facilities: asphalt and concrete. Third, parking garages and lots have different ambient lights levels due to the presence of additional reflective surfaces in parking garages (walls, ceilings, etc.), which may require different lighting levels.

Detection of an object (yes or no) was used as an objective measure of visual performance. The detection task consisted of facial and hand recognition, wheel stop detection, detection of a sidefacing pedestrian, and detection of a vehicle backing up from a parking spot. Safety, comfort, and visibility perceptions were assessed via a questionnaire. The detection tasks and the safety, comfort, and visibility perceptions were assessed from both pedestrians' and drivers' points of view. The independent variables used in this study and their levels are shown in Table 2. Because of differences in the drivers' and pedestrians' points of view, the objects used in the 
detection task were located at different distances, as indicated in Table 3, Figure 11, and Figure 12. The presentation of light levels was counterbalanced across participants to reduce orderrelated confounding effects. The order of presentation of detection tasks was randomized with blank presentations (no objects presented for detection) included as catch trials. The experiments were conducted only when the ambient temperature was higher than $45^{\circ} \mathrm{F}$ (including wind chill). The experimental session took place on clear nights (no rain, fog, or snow) after civil twilight (typically after 8:00 p.m. when ambient illuminance was $<0.03$ lux). The experiment lasted from early summer to mid fall. The surrounding noise levels in the parking facilities were not measured, but were typical of those in a parking facility with minimal pedestrian and vehicular activity.

Table 2. Independent variables and their levels.

\begin{tabular}{|l|l|l|}
\hline Variable & Levels - Parking Lot & Levels - Parking Garage \\
\hline Light Source Type & $\begin{array}{l}3000 \text { K Light-Emitting Diode } \\
\text { (LED) }\end{array}$ & $\begin{array}{l}3000 \text { K LED } \\
5000 \text { K LED } \\
\text { HPS } \\
\text { 5000 K LED } \\
\text { High-Pressure Sodium (HPS) }\end{array}$ \\
\hline Light Level (average) & $1,2,5,10$ and 12.5 lux & $2,4,10$ and 12.5 lux \\
\hline Age & $\begin{array}{l}18 \text { to 35 years } \\
65+\text { years }\end{array}$ & $\begin{array}{l}18 \text { to } 35 \text { years } \\
65+\text { years }\end{array}$ \\
\hline
\end{tabular}

\subsection{Detection Tasks}

Based on the gaps in research, the following list of critical visual tasks were identified for this study (Figure 1).

Figure 1. List of critical visual tasks for drivers and pedestrians. 
From the critical visual tasks, the following detection tasks were used to measure visual performance.

\subsubsection{Wheel Stop Detection}

Detection of wheel stops involved several commercially available wheel stops (Figure 2) of different colors (length $=6 \mathrm{ft}$.) to increase the external validity of the results. This task was presented at distances of 10 and $50 \mathrm{ft}$. for pedestrians and at 25 and $50 \mathrm{ft}$. for drivers. The luminances of all wheel stops were measured with a calibrated photometer (ProMetric PM9913E-1, Radiant Imaging ${ }^{\circledR}$, Redmond, WA) from the pedestrians’ and drivers’ (inside the vehicle) points of view for each light source type and at each light level to ensure that the light levels for each wheel stop were matched.

Figure 2. Wheel stops used in the detection task.

\subsubsection{Facial \& Hand Recognition}

Facial recognition involved the detection of glasses on an experimenter's face (Figure 3a and b). Hand recognition involved the detection of an experimenter's hands. As a control condition, experimenters were also presented with hands behind their back (Figure 3a-c). This task was presented at distances of 10 and $50 \mathrm{ft}$. for pedestrians and at a distance of $50 \mathrm{ft}$. for drivers. These distances were selected based on prior research on the distances at which people generally perceive threats in an outdoor environment (Fotios and others 2017; Fotios and others 2015b; Townshend 1997). 
Figure 3. Facial recognition involved detection of glasses (a) and (b). Hand recognition involved detection of hands (a) and (c).

\subsubsection{Detection of Side-Facing Pedestrian}

This task simulated the detection of a pedestrian walking out from behind a parked vehicle (Figure 4). This task was only presented at a distance of $50 \mathrm{ft}$. from the participant’s location for both pedestrians and drivers.

Figure 4. Detection of a side-facing pedestrian.

\subsubsection{Pedestrian Detection at Stopping Sight Distance}

This task was only performed for drivers as it simulated driver detection of a pedestrian in a parking garage (see Figure 5). A stopping sight distance of $155 \mathrm{ft}$. was selected based on a speed of $25 \mathrm{mph}$.

Figure 5. Pedestrian detection at the stopping sight distance.

\subsubsection{Detection of Reversing Vehicles}

This task simulated the detection of vehicles about to reverse out of a parking space with reverse and tail lamps on (Figure 6). Two identical 2017 Ford Explorers were used for this task.

Figure 6. Detection of a reversing vehicle.

Table 3. Critical tasks in the visual performance experiment. 


\begin{tabular}{|l|l|l|l|l|l|}
\hline Observer & $\begin{array}{l}\text { Wheel stop } \\
\text { Detection Task } \\
\text { (six different } \\
\text { colors) }\end{array}$ & $\begin{array}{l}\text { Face \& Hand } \\
\text { Recognition } \\
\text { Task }\end{array}$ & $\begin{array}{l}\text { Side-Facing } \\
\text { Pedestrian } \\
\text { Detection } \\
\text { Task }\end{array}$ & $\begin{array}{l}\text { Vehicle } \\
\text { Reversing } \\
\text { Detection } \\
\text { Task }\end{array}$ & $\begin{array}{l}\text { Pedestrian } \\
\text { Detection at } \\
\text { Stopping Sight } \\
\text { Distance Task } \\
\text { (only for Driver) }\end{array}$ \\
\hline Pedestrian & $10 \mathrm{ft}$ and $50 \mathrm{ft}$. & $\begin{array}{l}10 \mathrm{ft} \text { and } 50 \\
\mathrm{ft} \text { (right and } \\
\text { left side) }\end{array}$ & $50 \mathrm{ft}$. & $\begin{array}{l}50 \mathrm{ft} \text { (right } \\
\text { and left side) }\end{array}$ & $\mathrm{X}$ \\
\hline Driver & $25 \mathrm{ft}$ and $50 \mathrm{ft}$. & $\begin{array}{l}50 \mathrm{ft} \text { (right } \\
\text { and left side) }\end{array}$ & $50 \mathrm{ft.}$ & $\begin{array}{l}50 \mathrm{ft} \text { (right } \\
\text { and left side) }\end{array}$ & $155 \mathrm{ft.}$ \\
\hline
\end{tabular}

\subsection{Independent Variables}

\subsubsection{Light Source Type}

Three lights with different spectral power distributions (Figure 7) were selected to understand the effects of light source type on visual performance in parking garages (Figure 8) and lots. The parking lot with concrete pavement was evaluated only with a $5000 \mathrm{~K}$ LED light source as weather conditions made it impossible to continue with the experiment. The $3000 \mathrm{~K}$ and $5000 \mathrm{~K}$ LEDs represent the extremes of the range of commercially available CCTs for parking garage and lot applications. As a reference, an HPS light source (CCT $=2100 \mathrm{~K}$ ) was also used. The luminaires used in the parking garage had type V distributions, whereas those used in the parking lots had type III distributions. Illuminance uniformities (average to minimum [minimum to maximum]) were measured across all the light source types and light levels and were consistent at $5.0(0.1)$ for the parking garage and at $2.0(0.2)$ for the parking lot. The LED luminaires in the parking garage and parking lot had a Color Rendering Index (CRI) of 70, whereas the HPS luminaires had a CRI of 22.

Figure 7. Spectral power distributions of the three light sources used in the study. 
Figure 8. Three light sources used in the parking garage experiment from the driver's point of view. These pictures are of equal luminance $\left(0.86 \mathrm{~cd} / \mathrm{m}^{2}\right.$; average illuminance $\left.=10 \mathrm{lux}\right)$ and were captured with a calibrated photometer (ProMetric PM-9913E-1, Radiant Imaging ${ }^{\circledR}$ ).

\subsubsection{Light Level}

For the parking garage, four light levels were selected based on the maintained illuminance recommendation in RP-20-14 of 10 lux for parking garages. Two light levels below (2 and 4 lux) and one light level over (12.5 lux) the recommended light level were selected to understand the effect of light level on visual performance.

For the parking lots, five light levels were selected based on the illuminance recommendations in RP-20-14 of 5 lux for parking lots with asphalt pavement. Two light levels below (1 and 2 lux) and two levels over (10 and 12.5 lux) the recommended light level were selected to understand the effect of light level on visual performance.

The above light levels were the average horizontal pavement illuminance levels measured between a cycle of luminaires at the study sites. Dimming was achieved using combinations of neutral density filters attached to the front of an occlusion screen because dimming the HPS light source with a dimming ballast altered the spectral power distribution, especially at the lowest light levels. For consistent methodology across all light sources, the same dimming method was also used for both LED sources. Luminances were measured from drivers’ and pedestrians’ points of view (behind the occlusion screen, accounting for the transmissivity loss through the screen) to ensure that they were matched across all the light sources at each light level and location. This method of dimming did not alter the uniformity of the light sources across the different light levels. 
Spectral power distribution (SPD) measurements of all light sources taken with a spectroradiometer (Ocean Optics® HR2000CG-UV-NIR) with neutral density filter combinations for each light level and light source indicated that the filters did not affect the SPDs. Average pavement luminance measurements taken with a calibrated photometer (ProMetric PM-9913E-1, Radiant Imaging ${ }^{\circledR}$ ) showed that light levels were matched across light sources in the parking garage and lots (Table 4 and Table 5).

Table 4. Average luminance measurements in the parking garage for pedestrians and drivers.

\begin{tabular}{|l|l|r|r|r|r|}
\hline Observer & Light Source Type & 2 lux & \multicolumn{1}{l|}{ 4 lux } & \multicolumn{1}{c|}{ 10 lux } & 12.5 lux \\
\hline \multirow{4}{*}{ Pedestrian } & 3000 K LED & 0.15 & 0.31 & 0.86 & 1.19 \\
\cline { 2 - 7 } & 5000 K LED & 0.17 & 0.31 & 0.85 & 1.19 \\
\cline { 2 - 7 } & HPS & 0.14 & 0.31 & 0.86 & 1.18 \\
\hline \multirow{3}{*}{ Driver } & 3000 K LED & 0.19 & 0.34 & 0.94 & 1.29 \\
\cline { 2 - 6 } & 5000 K LED & 0.18 & 0.33 & 0.87 & 1.26 \\
\cline { 2 - 6 } & HPS & 0.18 & 0.33 & 0.91 & 1.26 \\
\hline
\end{tabular}

Table 5. Average luminance measurements in the parking lots for pedestrians and drivers.

\begin{tabular}{|c|c|c|c|c|c|c|}
\hline Observer & Light Source Type & 1 lux & $2 \operatorname{lux}$ & $5 \operatorname{lux}$ & 10 lux & 12.5 lux \\
\hline \multirow{3}{*}{ Pedestrian } & 3000 K LED & 0.12 & 0.16 & 0.47 & 0.89 & 1.23 \\
\hline & 5000 K LED & 0.12 & 0.18 & 0.44 & 0.91 & 1.20 \\
\hline & HPS & 0.12 & 0.16 & 0.45 & 0.87 & 1.22 \\
\hline \multirow{3}{*}{ Driver } & 3000 K LED & 0.14 & 0.21 & 0.58 & 0.94 & 1.31 \\
\hline & 5000 K LED & 0.14 & 0.20 & 0.57 & 0.99 & 1.30 \\
\hline & HPS & 0.13 & 0.20 & 0.54 & 0.97 & 1.28 \\
\hline
\end{tabular}

\subsubsection{Age}

Two different age ranges were selected (18-35 years and 65+ years) to account for agerelated physiological eye changes along with a range of safety perceptions. 


\subsection{Dependent Variables}

\subsubsection{Detection}

A binary variable of detection (yes or no) was used as a dependent measure for visual performance in the detection tasks.

\subsubsection{Perception of Visibility, Comfort, and Safety}

Subjective ratings on a five-point Likert scale (Figure 9) were used as dependent variables to assess visibility, comfort, and safety perceptions. The questionnaire was pilot tested $(n=3)$ to ensure participants understood the statements and the goal of the questionnaire. The questionnaire was divided into three areas: visibility, comfort, and safety. Visibility was assessed by statements 1-7. Comfort and safety were assessed by statements 8 and 9, respectively.

Figure 9. Likert scale questionnaire used for safety, comfort, and visibility perceptions.

\subsection{Participants}

Participants were recruited using the participant database of the Virginia Tech Transportation Institute (VTTI) and through word of mouth. Participants fell into two age- and gender-balanced groups: 18-35 years old and 65+ years old. All were residents of a mid-Atlantic state, had a visual acuity $\geq 20 / 40$ (measured by Early Treatment Diabetic Retinopathy Study chart with an illuminator cabinet), and were not color blind (measured by Ishihara Color Vision test). All experimental protocols were approved by an Institutional Review Board, and all participants provided written informed consent prior to any data collection.

For each of the three experiments, 24 participants were used. Overall, 72 participants completed the study. Participant demographics (means $[M]$ and standard deviations $[S D]$ ) for each of the 
three experiments are shown in Table 6.

Table 6. Demographic information of participants in the three experiments.

\begin{tabular}{|l|l|l|}
\hline Experiment & Young & Older \\
\hline Parking Garage $(n=24)$ & $\begin{array}{l}M=25.1 \text { years; } S D=3.6 \\
\text { years }\end{array}$ & $\begin{array}{l}M=66.5 \text { years; } S D=1.6 \\
\text { years }\end{array}$ \\
\hline Parking Lot - Asphalt & $M=24.7$ years; $S D=2.9$ & $M=68.1$ years; $S D=1.3$ \\
Pavement $(n=24)$ & years & $\begin{array}{l}M=69.9 \text { years; } S D=3.7 \\
\text { Parking Lot }- \text { Concrete }\end{array}$ \\
Pavement $(n=24)$ & $\begin{array}{l}M=24.6 \text { years; } S D=3.7 \\
\text { years }\end{array}$ & \\
\hline
\end{tabular}

\subsection{Procedure}

Up to two participants were scheduled at the same time. Upon arrival, participants reviewed the informed consent and performed a basic visual acuity test and Ishihara color vision test. Those not meeting the visual acuity or color vision criteria were excluded from the remainder of the study. Participants were then given detailed instructions regarding the experimental tasks, and provided an opportunity to ask questions. Participants were driven to the experimental locations. Upon arrival participants were given 10 minutes to adapt to their surroundings prior to the start of the experimental session.

\subsubsection{Pedestrian Task}

Participants assigned to the pedestrian task were instructed to stand behind an occlusion screen (transmittance $=0.83$ ) mounted on a tripod, which was connected to a computer in the experimental vehicle (Figure 10). The experimenter handed each participant a pen and a clipboard with the Participant Response Sheet and then walked participants through several practice trials before starting data collection. 
Figure 10. Viewing a scene with a wheel stop and side-facing pedestrian (behind the vehicle) through the occlusion screen.

Figure 11. Object locations for the pedestrian detection task.

Participants looked through the occlusion screen facing the parking area. When the shutter was closed, the occlusion screen scattered the light and took on a white texture; this prevented participants from perceiving visual information on the other side of the screen while maintaining adaptation luminance. When the shutter was open, looking through the screen was like looking through a clear glass pane. Experimenters placed the following objects in the parking area ahead of the participant while their vision was obscured: an experimenter posing as a pedestrian, wheel stops of varying colors (see Figure 2), or parked vehicles with their brake lights on. Objects were placed at different locations and at different distances from participants (Table 3, Figure 11, and Figure 12). Two types of pedestrians appeared: a front-facing pedestrian (with or without glasses, and with their hands behind their back or by their side) and a side-facing pedestrian (behind a parked vehicle). Once the objects were ready, the experimenter pressed a button, causing the occlusion screen to become clear for participants to observe the objects for one second before becoming opaque again. Multiple shutter open durations were piloted tested based on existing research (Fotios and others 2016; Fotios and others 2015b; Muttart and others 2017). Two issues were encountered for shutter-open durations $<1 \mathrm{~s}$ : (1) the lag from the occlusion screen's microcontroller resulted in inconsistent shutter-open times; and (2) facial and hand recognition were almost impossible to perform, even at the highest light levels. Both issues were resolved by using a shutter-open time of $1 \mathrm{~s}$. Once the screen became opaque again, participants indicated what object they saw by placing check marks on the Participant Response Sheet (only 
one object was presented per exposure). Experimenters placing the wheel stops were trained to place them quietly so that they would not alert participants. In the rare event that a wheel stop was placed loudly, the condition was repeated without the participant's knowledge during the same session.

While participants filled out the Participant Response Sheet, experimenters readied the next two objects. This process was repeated until all conditions were shown at the current light level (36 total presentations). Once all conditions were completed, participants answered a questionnaire asking how much they agreed or disagreed with a series of statements about the parking garage/lot lighting.

The light level was then changed, and the entire process was repeated. Participants performed these tasks four times (one for each light level). An anti-fatigue mat was provided for participants to stand on, and a chair was provided if they needed to take a short break from standing.

\subsubsection{Driver Task}

Participants assigned to the driving task were asked to sit in the driver's seat of a 2002 Cadillac Escalade parked in the parking lot/garage and were given a moment to adjust the seat, steering wheel, and mirrors. The vehicle had halogen headlamps which were on and in the lowbeam configuration. Headlamps were cleaned and aimed prior to each experimental session. The vehicle’s windshield was also thoroughly cleaned before every session. Participants sat in the driver's seat of the vehicle and performed the same object detection tasks as those in the Pedestrian Task (but at different distances; Figure 12) while looking through an occlusion screen mounted inside the vehicle. After finishing the detection tasks at each light level, participants 
were handed a paper questionnaire and asked to indicate how much they agreed or disagreed with statements about the parking lot lighting. Participants repeated this process for all light levels: four times for the parking garage and five times for the parking lots. In the second and third sessions, participants repeated the same experimental tasks from the first session under different lighting conditions. The experimental sessions in the parking garage and lots lasted about 35 minutes and about 60 minutes respectively.

Figure 12. Object locations for the driver detection task.

\subsection{Analysis}

\subsubsection{Sensitivity Analysis}

To ensure that participants responded appropriately to the presented objects rather than responding randomly or guessing, a sensitivity analysis was conducted by calculating the dprime scores of participant responses. The d-prime score is the difference between the Z-scores (or $\mathrm{Z}$ transformations) of the hit-rate (detecting an object when it is present) and false-alarm rate (detecting an object when nothing is present). The larger this difference, the better the participant performance or sensitivity (Fotios and Cheal 2012). The d-prime scores along with their hit rates and false-alarm rates are indicated in Table 7. The high d-prime scores (greater than 2) show that participants had high sensitivity and responded only when objects were presented.

Table 7. Hit rates, false-alarm rates and d-prime scores of participants under each light type at each location.

\begin{tabular}{|c|c|c|c|c|c|c|c|c|c|}
\hline & \multicolumn{3}{|c|}{ HPS } & \multicolumn{3}{|c|}{3000 K LED } & \multicolumn{3}{|c|}{5000 K LED } \\
\hline Location & $\begin{array}{l}\text { Hit } \\
\text { Rate }\end{array}$ & $\begin{array}{l}\text { False } \\
\text { Alarm } \\
\text { Rate } \\
\end{array}$ & d-prime & $\begin{array}{l}\text { Hit } \\
\text { Rate }\end{array}$ & $\begin{array}{l}\text { False } \\
\text { Alarm } \\
\text { Rate } \\
\end{array}$ & d-prime & $\begin{array}{l}\text { Hit } \\
\text { Rate }\end{array}$ & $\begin{array}{l}\text { False } \\
\text { Alarm } \\
\text { Rate } \\
\end{array}$ & d-prime \\
\hline
\end{tabular}




\begin{tabular}{|l|c|c|r|r|r|r|r|r|r|}
\hline $\begin{array}{l}\text { Parking } \\
\text { Garage }\end{array}$ & $77.7 \%$ & $0.3 \%$ & 3.50 & $82.0 \%$ & $1.5 \%$ & 3.08 & $78.4 \%$ & $0.2 \%$ & 3.61 \\
\hline $\begin{array}{l}\text { Parking Lot - } \\
\text { Asphalt }\end{array}$ & $79.6 \%$ & $4.0 \%$ & 2.57 & $77.3 \%$ & $2.2 \%$ & 2.77 & $69.3 \%$ & $3.5 \%$ & 2.32 \\
\hline $\begin{array}{l}\text { Parking Lot - } \\
\text { Concrete }\end{array}$ & NA & NA & NA & NA & NA & NA & $70.1 \%$ & $1.7 \%$ & 2.65 \\
\hline
\end{tabular}

NA - Not Applicable - no data was collected

\subsubsection{Visual Performance Analysis}

Three repeated measures logistic regression models (one for the parking garage, one for the asphalt parking lot, and one for the concrete parking lot) were used to assess the effects of light source type, light level, type of critical task, and type of observer on detection performance in critical visual tasks. For all logistic regression models, one four-way interaction term involving light source type, light level, type of observer, and age was included along with the main effects. The four-way interaction helped isolate the effects of light level on visual performance under each lighting condition, each observer, and each age group. This interaction also allowed pedestrian data to be analyzed separately from driver data so that the former were not affected by confounding effects such as headlamps. Logistic regression allows the estimate of a specific factor to be considered as an averaged value over all the levels of other factors included in the same model. Thus, the confounding effect can be effectively addressed by simply including multiple factors that might simultaneously confound each other in the model. By including all critical tasks in the logistic regression models, the effects of light source type and light level on visual performance can be interpreted as an aggregate of all critical tasks, thereby eliminating the need to analyze the visual performance for each task separately. The level of significance was $p<0.05$ for all statistical tests. Where relevant, post hoc comparisons were performed using Tukey’s honest significant difference. Logistic regression produced odds ratios 
for factors in the model. However, herein, back-transformed estimated detection probabilities and their associated standard errors are reported.

The plateau in detection with increasing illuminance was examined based on the effect of illuminance on detection probabilities for each light source type. A plateau was considered to occur when an increase in light level did not result in a corresponding statistically significant increase in detection probability in the post hoc pairwise comparisons. The ratio of generalized chi-square to its degrees of freedom for each of the three repeated measures logistic regression models was close to one, indicating that there was no residual overdispersion and that the variability was accurately modelled.

Because it was difficult to change the luminaires in the parking garage and lots, the order of presentation of the light sources could not be counterbalanced. As a result, a confounding learning effect was anticipated as participant performance was expected to improve with each experimental session under each light source. This was particularly true in the parking lots, where the experimental sessions were approximately 30 min longer than in the parking garage. To test for this confounding effect, at the end of the study, a small sample of new participants ( $n$ = 3) was exposed to the last-presented light source (HPS) in the asphalt parking lot. The performances of these new participants were compared to those of the original participants for the HPS light source to identify any confounding learning effect.

\subsubsection{Subjective Ratings Analysis}

For each location, three separate linear mixed models (LMMs) were performed for each dimension: visibility, comfort, and safety. Inter-item reliability for visibility perceptions was assessed using Cronbach’s alpha for all questionnaire statements (Figure 9). Additional analyses 
were only conducted for Cronbach's alpha $>0.7$, indicating a high inter-item reliability in the questionnaire responses (Bernstein and Nunnally 1994). Standardized Cronbach’s alpha values for visibility perceptions in the parking garage, asphalt parking lot, and concrete parking lot were 0.91, 0.89, and 0.82, respectively, indicating a high level of reliability. Thus, composite Likert scores were calculated by averaging the responses across statements 1-7 at each location (Boone and Boone 2012; Sullivan and Artino Jr 2013). These composite Likert scores were used as dependent measures in the subjective analysis of visibility perception. For perceptions of comfort and safety, Likert scores for statements 8 and 9 were used as dependent measures.

Overall, nine separate LMMs were used to assess the effects of light source type and light level on visibility, comfort, and safety perceptions. Participant age group was used as a blocking variable. Like the visual performance analysis, level of significance was established at $p<0.05$, and post hoc comparisons were performed using Tukey’s honest significant difference. Plateauing in subjective ratings was determined by examining post hoc pairwise comparisons, similar to the methodology used in visual performance analysis.

\section{Results}

\subsection{Parking Garage}

\subsubsection{Visual Performance}

Results from the repeated measures logistic regression model for the parking garage are shown in Table 8. All main effects were significant except observer. The four-way interaction involving age, light source type, light level, and observer was also significant.

Table 8. Repeated measures logistic regression analysis at parking garage. 


\begin{tabular}{|l|l|l|r|r|}
\hline Effect & $\begin{array}{l}\text { Numerator (Num) } \\
\text { DF }\end{array}$ & $\begin{array}{l}\text { Denominator (Den) } \\
\text { DF }\end{array}$ & F Value & P Value \\
\hline Age (A) & 1 & 11029 & 15 & 0.0001 \\
\hline Light Source Type (LST) & 2 & 11029 & 20.26 & $<0.0001$ \\
\hline Light Level (LL) & 3 & 11029 & 42 & $<0.0001$ \\
\hline Task (T) & 24 & 11029 & 33.71 & $<0.0001$ \\
\hline Observer (O) & 1 & 11029 & 4.39 & 0.0362 \\
\hline A x LST x LL x O & 40 & 11029 & 1.96 & 0.0003 \\
\hline
\end{tabular}

The interaction was subsequently analyzed to understand the effects of light level on detection probability for each observer type at each age and light source type (Figure 13). Statistically significant increases in estimated detection probabilities with increase in light level were only observed for the HPS light source in younger pedestrians and drivers, for the $3000 \mathrm{~K}$ LED in older pedestrians, and for the $5000 \mathrm{~K}$ LED in older drivers. In each of these instances, detection probabilities between 2-10 lux and 2-12.5 lux were significant. This indicates that beyond 10 lux, there was no significant increase in the detection probability across all observers, ages, and light source types. Older participants had lower detection probabilities than younger participants, especially at lower light levels (Figure 13). Older drivers had higher detection probabilities than older pedestrians at the lowest light level. Light source type did not significantly affect the detection of different colored wheel stops. However, there were differences in wheel stop detection probabilities based on color and observer. For pedestrians, at a distance of $10 \mathrm{ft}$., dark gray wheel stops had the lowest detection probability (Figure 14a), and at $50 \mathrm{ft}$., light gray stops had the lowest detection probability (Figure 14b). For drivers, dark gray wheel stops had the lowest detection probability at both 25 and $50 \mathrm{ft}$. (Figure 14c and d).

Figure 13. Interactive effect of age, observer, light source type, and light level on detection probabilities in parking garages. Uppercase letters denote significant differences between light 
levels from pairwise comparisons $(p<0.05)$. Values are least square means of estimated detection probabilities and error bars represent standard errors.

Figure 14. Effect of wheel stop color on detection probabilities for pedestrians and drivers at different distances.

\subsubsection{Subjective Ratings}

The results of the LMM, which analyzed the effects of light source type, light level, and age on perceptions of visibility, comfort, and safety are shown in Table 9.

Table 9. LMM analyses of subjective ratings at parking garage.

\begin{tabular}{|c|c|c|c|}
\hline Effect & Visibility & Comfort & Safety \\
\hline LST & $\begin{array}{l}F(2,61.6)=7.02 \\
p=0.0018\end{array}$ & $\begin{array}{l}F(2,72)=4.37, p \\
=0.0162\end{array}$ & $\begin{array}{l}F(2,67.7)=6.12, \\
p=0.0036\end{array}$ \\
\hline LL & $\begin{array}{l}F(3,178)=51.22, \\
p<0.0001\end{array}$ & $\begin{array}{l}F(3,181)= \\
24.83, p<0.0001\end{array}$ & $\begin{array}{l}F(3,182)= \\
30.59, p<0.0001\end{array}$ \\
\hline A x LL & $\begin{array}{l}F(3,178)=5.15, p \\
=0.0019\end{array}$ & \multirow{3}{*}{ NS } & NS \\
\hline A $x$ LST & NS & & $\begin{array}{l}F(2,67.7)=3.14, \\
p=0.0498\end{array}$ \\
\hline$A \times L L \times O$ & NS & & $\begin{array}{l}F(3,183)=3.31, \\
p=0.0213\end{array}$ \\
\hline
\end{tabular}

In general, increasing light level corresponded to increased visibility, safety, and comfort perceptions (Figure 15). Pairwise comparisons indicated no statistically significant increase in visibility, safety, and comfort perceptions beyond 10 lux. Perceptions of visibility, comfort, and safety were highest for the $5000 \mathrm{~K}$ LED (Figure 16), and only the differences between $5000 \mathrm{~K}$ LED and 3000 K LED were statistically significant. 
Figure 15. Effect of light level on visibility, comfort, and safety perceptions. Uppercase letters denote significant differences from pairwise comparisons $(p<0.05)$. Values are least score means of ratings of Likert composite scores and error bars represent standard errors.

Figure 16. Effect of light source type on visibility, comfort, and safety perceptions. Uppercase letters denote significant differences from pairwise comparisons $(\mathrm{p}<0.05)$. Values are least score means of ratings of Likert composite scores and error bars represent standard errors.

\subsection{Parking Lot}

\subsubsection{Asphalt Pavement - Visual Performance}

The results of the repeated measures logistic regression models for the parking lot with asphalt pavement reveal that the main effects along with the four-way interaction involving all main effects were significant (Table 10).

Table 10. Repeated measures logistic regression analysis: parking lot with asphalt pavement.

\begin{tabular}{|l|r|r|r|c|}
\hline Effect & Num DF & Den DF & F Value & P Value \\
\hline Age (A) & 1 & 13541 & 27.34 & $<0.0001$ \\
\hline Light Source Type (LST) & 2 & 13541 & 83.2 & $<0.0001$ \\
\hline Light Level (LL) & 4 & 13541 & 148.61 & $<0.0001$ \\
\hline Task (T) & 24 & 13541 & 56.57 & $<0.0001$ \\
\hline Observer (O) & 1 & 13541 & 7.62 & 0.0058 \\
\hline A x LST x LL x O & 51 & 13541 & 4.41 & $<0.0001$ \\
\hline
\end{tabular}

An increase in detection probability was consistently observed between 1 and 2 lux across all light source types, ages, and observers. Beyond 2 lux, increase in detections was not apparent (Figure 17). For older drivers only, plateauing in estimated detection probabilities was observed at 2 and 5 lux. Detection probabilities for older participants were lower than for younger 
participants, especially at lower light levels (Figure 17). Drivers of both ages groups also had higher detection probabilities at the lowest light level than pedestrians, but the differences were highest for older drivers (Figure 17). Detection probabilities observed for the 5000 K LED were lower than those for the HPS and $3000 \mathrm{~K}$ LED light sources, possibly as a result of an unavoidable order-related learning effect. When a sample of new participants $(n=3)$ were first exposed to the HPS light source, their detection performance closely resembled the performance for the $5000 \mathrm{~K}$ LED, indicating such an effect (Figure 18). The magnitude of the learning effect was higher in the older than in younger pedestrian group as evidenced by the higher increases in detection probabilities between the HPS and 5000 K LED (Figure 19).

Figure 17. Interactive effect of age, observer, light source type, and light level on detection. Uppercase letters denote significant differences between light levels from pairwise comparisons $(\mathrm{p}<0.05)$. Values are least square means of estimated detection probabilities and error bars represent standard errors.

Figure 18. Presence of a learning effect demonstrated by similar mean detection rates for participants who experienced HPS light source first vs. 5000 K LED first.

Figure 19. Differences in the detection probabilities across older and younger pedestrians between HPS and $5000 \mathrm{~K}$ LED light source types.

Light source type did not significantly affect the detection of different colored wheel stops. However, wheel stop color affected its detection probability (Figure 20). Dark gray wheel stops had the lowest detection probabilities for drivers (at $25 \mathrm{ft}$.) and pedestrians (at $10 \mathrm{ft}$. and $50 \mathrm{ft}$.). 
For drivers at $50 \mathrm{ft}$., both the dark and light gray wheel stops had the lowest detection probabilities.

Figure 20. Effect of wheel stop color on detection probabilities for pedestrians and drivers at different distances in the parking lot with asphalt pavement.

\subsubsection{Asphalt Pavement - Subjective Ratings}

The results of the LMM, which analyzed the effect of light source type, light level, and age on visibility, comfort, and safety perceptions at parking lots with asphalt pavement are shown in Table 11.

Table 11. LMM analyses of subjective ratings at parking lot with asphalt pavement.

\begin{tabular}{|c|c|c|c|}
\hline Effect & Visibility & Comfort & Safety \\
\hline LST & $\begin{array}{l}F(2,83.8)=17.23, \\
p<0.0001\end{array}$ & $\begin{array}{l}F(2,93)=11.08 \\
p<0.0001\end{array}$ & $\begin{array}{l}F(2,82.2)=9.52 \\
p=0.0002\end{array}$ \\
\hline LL & $\begin{array}{l}F(4,221)=107.53 \\
p<0.0001\end{array}$ & $\begin{array}{l}F(4,217)=96.28 \\
p<0.0001\end{array}$ & $\begin{array}{l}F(4,223)=88.15, \\
p<0.0001\end{array}$ \\
\hline$A \times L L$ & $\begin{array}{l}F(4,221)=5.24 \\
p=0.0005\end{array}$ & NS & NS \\
\hline LL x O & $\begin{array}{l}F(4,221)=7.87, \\
p<0.0001\end{array}$ & $\begin{array}{l}F(4,217)=5.72 \\
p=0.0002\end{array}$ & $\begin{array}{l}F(4,223)=6.22, \\
p<0.0001\end{array}$ \\
\hline LST x LL & $\begin{array}{l}F(8,234)=2.14 \\
p=0.0329\end{array}$ & NS & \multirow{4}{*}{ NS } \\
\hline A $x \operatorname{LST} \times 0$ & $\begin{array}{l}F(2,83.4)=3.19 \\
p=0.0462\end{array}$ & $\begin{array}{l}F(2,92.5)=4.19 \\
p=0.0182\end{array}$ & \\
\hline$A \times L L \times O$ & $\begin{array}{l}F(4,221)=3.92 \\
p=0.0043\end{array}$ & \multirow{2}{*}{ NS } & \\
\hline A x LST x LL x O & $\begin{array}{l}F(8,234)=2.15 \\
p=0.0319\end{array}$ & & \\
\hline
\end{tabular}

In the parking lot with asphalt pavement, increase in light level also resulted in an increase in visibility, comfort, and safety perceptions (Figure 21). Beyond 2 lux, increases in light level did not result in a statistically significant increase in subjective ratings of visibility, comfort, or safety (Figure 21). Both 5000 and the 3000 K LEDs had the highest ratings of visibility, safety, 
and comfort and these ratings were significantly higher than those observed in the HPS light source type (Figure 22).

Figure 21. Effect of light level on visibility, safety, and comfort perceptions at the parking lot with asphalt pavement. Uppercase letters signify significant differences from pairwise comparisons ( $\mathrm{p}$ <.05). Values are least score means of ratings of Likert composite scores and error bars represent standard errors.

Figure 22. Effect of light source type on visibility, safety, and comfort perceptions at the parking lot with asphalt pavement. Uppercase letters denote significant differences from pairwise comparisons ( $\mathrm{p}<0.05)$. Values are least score means of ratings of Likert composite scores and error bars represent standard errors.

\subsubsection{Concrete Pavement - Visual Performance}

The results of the repeated measures logistic regression models for the parking lot with concrete pavement are shown in Table 12.

Table 12. Repeated measures logistic regression analysis. Significant effects are highlighted in bold font.

\begin{tabular}{|l|r|r|r|r|}
\hline Effect & Num DF & Den DF & F Value & P Value \\
\hline Age (A) & $\mathbf{1}$ & $\mathbf{5 6 2 5}$ & $\mathbf{9 . 5 2}$ & $\mathbf{0 . 0 0 2 0}$ \\
\hline Light Level (LL) & $\mathbf{4}$ & $\mathbf{5 6 2 5}$ & $\mathbf{4 1 . 6 5}$ & $<\mathbf{0 . 0 0 0 1}$ \\
\hline Task (T) & $\mathbf{2 6}$ & $\mathbf{5 6 2 5}$ & $\mathbf{2 1 . 4 4}$ & $<\mathbf{0 . 0 0 0 1}$ \\
\hline Observer (O) & 1 & 5625 & 2.51 & 0.1132 \\
\hline A x LL x O & $\mathbf{1 3}$ & $\mathbf{5 6 2 5}$ & $\mathbf{3 . 9 1}$ & $<\mathbf{0 . 0 0 0 1}$ \\
\hline
\end{tabular}

Similar to the asphalt pavement parking lot, the biggest increases in detection probabilities were observed between 1 and 2 lux. Beyond 2 lux, statistically significant increases in detection probabilities with increase in light level were not observed (Figure 23). Older pedestrians had 
lower detection probabilities than younger pedestrians (Figure 23). Older drivers also had higher detection probabilities than older pedestrians at every light level except 12.5 lux.

Figure 23. Interactive effects of age and light level on detection probabilities for pedestrians and drivers. Uppercase letters denote significant differences between light levels from pairwise comparisons $(\mathrm{p}<0.05)$. Values are least square means of estimated detection probabilities and error bars represent standard errors.

Wheel stops' color also influenced their detection (Figure 24). Dark gray wheel stops had the lowest detection probabilities for drivers at a distance of $25 \mathrm{ft}$. and for pedestrians at 10 and $50 \mathrm{ft}$. For drivers at $50 \mathrm{ft}$. , the light gray wheel stop had the lowest detection probability.

Figure 24. Effect of wheel stop color on detection probabilities for pedestrians and drivers at different distances at the parking lot with concrete pavement.

\subsubsection{Concrete Pavement - Subjective Ratings}

The results of the LMM, which analyzed the effect of light level and age on visibility, comfort, and safety perceptions at the parking lot with concrete pavement are shown in Table 13.

Table 13. Results of LMM analyses of subjective ratings at parking lot with concrete pavement. 


\begin{tabular}{|c|c|c|c|}
\hline Effect & Visibility & Comfort & Safety \\
\hline A & $\begin{array}{l}F(1,24.5)=5.62 \\
p=0.026\end{array}$ & NS & NS \\
\hline LL & $\begin{array}{l}F(4,76.5)=19.78, \\
p<0.0001\end{array}$ & $\begin{array}{l}F(4,82.2)=22.93 \\
p<0.0001\end{array}$ & $\begin{array}{l}F(4,82.3)=20.12, \\
p<0.0001\end{array}$ \\
\hline LL $x$ O & $\begin{array}{l}F(4,75.8)=4.1, \\
p=0.0046\end{array}$ & \multirow{4}{*}{ NS } & $\begin{array}{l}F(4,81.8)=3.15 \\
p=0.0185\end{array}$ \\
\hline$A \times L L$ & \multirow{3}{*}{ NS } & & $\begin{array}{l}F(4,82.3)=2.7 \\
p=0.0359\end{array}$ \\
\hline $\mathrm{A} \times \mathrm{O}$ & & & $\begin{array}{l}F(1,33.6)=6.75 \\
p=0.0138\end{array}$ \\
\hline$A \times L L \times O$ & & & $\begin{array}{l}F(4,81.8)=2.92 \\
p=0.026\end{array}$ \\
\hline
\end{tabular}

At the parking lot with concrete pavement, increase in light level resulted in an increase in visibility, comfort, and safety perceptions (Figure 25). Increases in ratings beyond 2 lux were not statistically significant for visibility, comfort, or safety (Figure 25).

Figure 25. Effect of light level on visibility, safety, and comfort perceptions at the parking lot with concrete pavement. Uppercase letters signify significant differences from pairwise comparisons $(\mathrm{p}<0.05)$. Values are least score means of ratings of Likert composite scores and error bars represent standard errors.

\section{Discussion}

The goal of this paper was to understand the effect of light source type and light level on visual performance and safety, comfort, and visibility perceptions in parking garages and lots for all users. The results of the study revealed four major findings. First, an increase in light levels resulted in an increase in the objective measures of visual performance and safety, comfort, and visibility perceptions across all parking facilities. Second, plateaus were observed in the visual performance and safety, comfort, and visibility perceptions and these occurred at different light levels across different parking facilities. Third, the effects of light source type on safety, comfort, 
and visibility perceptions were more evident than its effects on visual performance at all parking facilities. Fourth, younger participants had higher detection rates and visibility perceptions than older participants. These findings are discussed in more detail in the subsequent subsections.

\subsection{Effects of Light Level}

In general, under all light sources, tasks, and parking facility locations, an increase in light level resulted in an increase in the objective measures of visual performance as evidenced by the increase in detection probability. Increased light levels also resulted in increased perceived ratings of visibility, comfort, and safety. These increases could be attributed to the increased amount of visual information participants were able to extract from the area. The study's results are in agreement with existing research (Bhagavathula and others 2018; Boyce and Bruno 1999; Edwards and Gibbons 2008; Gibbons and others 2015; Janoff 1989; Minoshima and others 2006) evaluating the effect of light level on visual performance and perceptions of visibility.

There were differences in the light levels at which plateauing in visual performance was observed; these depended on location, age of the observer, light source type, and the observer. For example, in the parking garage, plateaus in visual performance were observed between 2 and 10 lux, whereas in the parking lot with asphalt pavement, plateaus were observed between 1 and 5 lux. For a majority of light sources, observers, and ages, plateaus were observed at 10 lux in the parking garage and at 2 lux in the parking lots. The plateauing at 2 lux in the parking lots is supported by a study that evaluated the detection of obstacles under different light sources and light levels (Fotios and Cheal 2009). It should be noted that the plateaus in visual performance reported here were observed within the ranges of illuminances used in this study (2-12.5 lux for 
the parking garage and 1-12.5 lux for the parking lots). Increase beyond those ranges could result in increased visual performance; however, those increases may also be marginal and thus not statistically significant.

Differences in the plateauing of visibility, comfort, and safety perceptions were also observed, but were limited to the locations. For example, in the parking garage, plateaus in all perceptions were observed at 10 lux, whereas in the parking lots, plateaus were observed at 2 lux. There were also differences in where the mean ratings exceeded the "neutral” anchor on the Likert scale in safety, comfort, and visibility perceptions. For the parking garage, this was observed at 4 lux, whereas in both parking lots, it was observed at 2 lux.

\subsection{Effects of Light Source}

The effect of light source was not consistent across the visual performance tasks and safety, comfort, and visibility perceptions. Within the visual performance tasks, the light source effects varied across observer and age. The effects of light source type were more evident for pedestrians than for drivers, which could be a direct result of the vehicle head lamps' impact. Spectral interactions between the vehicle headlamps and parking facility light source type were not observed, which is consistent with existing research (Gibbons and others 2015) showing that that in the presence of overhead lighting, SPD of the vehicle headlamps does not affect visual performance.

In the parking lots, the HPS light source outperformed the $5000 \mathrm{~K}$ LED as evidenced by the higher detection probabilities. These results were counterintuitive, as the $5000 \mathrm{~K}$ LED would be expected to perform better because higher CCT LEDs, in which light appears whiter, offer better color recognition capability (Boyce and Bruno 1999; Chen 1998; Fotios and Cheal 2007; Terry 
2011). These higher detection rates for the HPS light source could also be attributed to the orderrelated learning effect. Due to the nature of the experimental design, all participants in the parking lot with asphalt pavement experienced light sources in the same order (5000 K LED first, 3000 K LED second, and HPS last). By the time participants experienced the HPS light source, they had already performed similar tasks twice. Three new participants who were exposed to the HPS light source first performed similarly to the participants who were exposed to the $5000 \mathrm{~K}$ LED light source first, strongly indicating a possible learning effect. This effect was more pronounced in older participants than in younger participants as evidenced by the older group’s significantly higher detection rates under the HPS light source. Because of the learning effect, it is difficult to determine which light source offered the best visual performance. However, there were still notable consistently observed similar trends of an increase in the mean detection probability and of attaining a plateau across all light sources. No learning effects were observed for the parking garage, which could be due to the shorter duration of experimental sessions performed there — the parking garage experiment had four light levels whereas the parking lot experiments had five. Finally, the effects of light sources on subjective ratings could help determine the light source's effect on increased safety, comfort, and visibility perceptions.

The effect of light source type on visibility, comfort, and safety perceptions was observed for both pedestrians and drivers at all locations. In the parking lot with asphalt pavement, 5000 and 3000 K LED light sources had higher ratings than the HPS light source. The 5000 K LED and $3000 \mathrm{~K}$ LED had similar ratings across all rating areas. Higher LED ratings could be attributed to their whiter light compared to the yellowish light produced by the HPS light sources, as existing research shows that whiter lights are perceived to be brighter (Fotios and Cheal 2007; Johnson and others 2009; Knight 2010; Rea and others 2009). However, it is important to note that the 
$5000 \mathrm{~K}$ LED appeared to be whiter than the $3000 \mathrm{~K}$ LED, yet there were no statistically significant differences in perceived ratings. In the parking garage, light source type's effect on visibility, comfort, and safety perceptions was observed for both pedestrian and drivers, where the $5000 \mathrm{~K}$ LED had statistically higher ratings than the $3000 \mathrm{~K}$ LED. Interestingly, even though the $5000 \mathrm{~K}$ LED had higher ratings than the HPS light source, the differences between them was not statistically significant at the parking garage. Overall, these results indicate that for parking lots with asphalt pavement, LED light sources had the highest visibility, comfort, and safety perceptions, whereas for parking garages, the spectral power distribution did not seem to greatly influence any of these perceptions.

\subsection{Effects of Age}

Participant age affected visual performance tasks more than subjective ratings. Younger participants had higher detection probabilities than older participants. Older participants’ lower detection probabilities were due to age-related physiological changes in the eye, which negatively affect visual performance, and are in line with existing research (Bhagavathula and others 2018; Gibbons and others 2015; Owens and others 2007; Terry 2011). Age-related effects were more significant at the lowest light level (2 lux) than at higher levels, indicating that higher levels benefit older participants by increasing their visual performance. Older participants in the driver group had higher detection probabilities across all light sources than those in the pedestrian group, especially at the lowest light levels, which could be due to the additional illuminance from the headlamps positively influencing visual performance. This is further evidenced by the nearly identical detection probabilities at the 2, 5, and 10 lux between older and younger drivers at the parking lot with concrete pavement. 


\subsection{Practical Implications}

This study has important practical implications for recommended light levels for parking lots and garages. The results clearly show that visual performance and safety, comfort, and visibility perceptions plateau at an average pavement illuminance of 10 lux for all parking garage users (pedestrians and drivers). Results also show that $5000 \mathrm{~K}$ LEDs and HPS produce higher safety, comfort, and visibility perceptions, and increase the visual performance of all parking garage users at an average pavement illuminance of 10 lux.

Additionally, for parking lots with asphalt and concrete pavements, an average pavement illuminance of 2 lux can ensure a higher visual performance and greater safety, comfort, and visibility perceptions for all parking lot users. At an average pavement illuminance of 2 lux, the $5000 \mathrm{~K}$ and $3000 \mathrm{~K}$ LEDs led to higher safety, comfort, and visibility perceptions for all parking lot users.

Other interesting study results revealed that gray colored wheel stops (both dark and light colored) are not ideal for parking facilities, as they had the lowest detection probabilities across all locations, light types, light levels, observers, and ages, likely due to poor color contrast between the wheel stops and the pavement. Wheel stops with higher color contrasts, such as black and yellow, blue, white, and yellow, consistently had the highest detection probabilities.

\subsection{Limitations}

This study had some limitations. For example, the presence of order-related learning effects in the parking lot experiment masked the effect of light source on visual performance. This was unavoidable, as the task of installing and removing luminaires at the test location to counterbalance the exposures to participants would have unduly prolonged the experiment. Light sources with higher blue content (higher CCTs) could also increase peripheral visual 
performance, especially in the younger population. Participants in this study could have used peripheral vision for the detection task; the determination of peripheral vs. foveal vision could not be made as gaze direction was not actively controlled. Questionnaires used to understand the visibility, safety, and comfort perceptions did not have any negatively worded questions to check if participants were answering questions thoughtfully; however, the questionnaire was pilot tested extensively prior to the study to ensure it captured what it was designed for. Finally, the vehicle in the driver task was stationary, as it was difficult and potentially unsafe for participants to drive with the occlusion screen in front of them. Future work should address these limitations in order to add to the body of knowledge on visibility in parking facilities.

\section{Conclusion}

The following conclusions can be drawn from the study:

1. An increase in light levels results in an increase in visual performance and safety, comfort, and visibility perceptions. Increases in visual performance and safety, comfort, and visibility perception plateaued at an average pavement illuminance of 10 lux for parking garages and 2 lux for parking lots with asphalt and concrete pavements.

2. Light source type had a significant effect on safety, comfort, and visibility perceptions, where the $5000 \mathrm{~K}$ and $3000 \mathrm{~K}$ LEDs had the highest ratings in parking lots and the 5000 K LED had the highest ratings in the parking garage.

\section{Funding}

Funding for this research was provided by the Illuminating Engineering Society and Southern California Edison. 


\section{Disclosure Statement}

The authors have no interests to declare.

\section{References}

Adrian W. 1989. Visibility of targets: Model for calculation. Lighting Research and Technology 21(4):181-188.

Bernstein IH, Nunnally J. 1994. Psychometric theory. New York: McGraw-Hill.

Bhagavathula R. 2016. Effects of Intersection Lighting Design on Driver Visual Performance, Perceived Visibility, and Glare [Doctoral]. [Blacksburg, VA]: Virginia Tech. p. 103.

Bhagavathula R, Gibbons RB, Nussbaum MA. 2018. Effects of Intersection Lighting Design on Nighttime Visual Performance of Drivers. LEUKOS 14(1):25-43.

Boone HN, Boone DA. 2012. Analyzing likert data. Journal of extension 50(2):1-5.

Boyce P. 1973. Age, illuminance, visual performance and preference. Lighting Research and Technology 5(3):125-144.

Boyce P, Rea M. 1990. Security lighting: Effects of illuminance and light source on the capabilities of guards and intruders $†$. Lighting Research and Technology 22(2):57-79.

Boyce PR, Bruno LD. 1999. An evaluation of high pressure sodium and metal halide light sources for parking lot lighting. Journal of the Illuminating Engineering Society 28(2):1632.

Boyce PR, Eklund NH, Hamilton BJ, Bruno LD. 2000. Perceptions of safety at night in different lighting conditions. Lighting Research and Technology 32(2):79-91.

Caminada J, Van Bommel W. 1984. New lighting criteria for residential areas. Journal of the Illuminating Engineering Society 13(4):350-358. 
Chen L. 1998. The accuracy of color naming under different light sources at low photopic to low mesopic conditions. MSc thesis. Troy, New York: Rensselaer Polytechnic Institute.

Edwards C, Gibbons R. 2008. Relationship of vertical illuminance to pedestrian visibility in crosswalks. Transportation Research Record: Journal of the Transportation Research Board(2056):9-16.

Eloholma M, Ketomäki J, Orreveteläinen P, Halonen L. 2006. Visual performance in night-time driving conditions. Ophthalmic and Physiological Optics 26(3):254-263.

Fotios S, Castleton H, Cheal C, Yang B. 2017. Investigating the chromatic contribution to recognition of facial expression. Lighting Research \& Technology 49(2):243-258.

Fotios S, Cheal C. 2007. Lighting for subsidiary streets: investigation of lamps of different SPD. Part 1—Visual Performance. Lighting Research \& Technology 39(3):215-232.

Fotios S, Cheal C. 2009. Obstacle detection: A pilot study investigating the effects of lamp type, illuminance and age. Lighting Research and Technology 41(4):321-342.

Fotios S, Cheal C. 2012. Using obstacle detection to identify appropriate illuminances for lighting in residential roads. Lighting Research and Technology:1477153512444112.

Fotios S, Uttley J, Cheal C, Hara N. 2015a. Using eye-tracking to identify pedestrians’ critical visual tasks, Part 1. Dual task approach. Lighting Research and Technology 47(2):133148.

Fotios S, Uttley J, Fox S. 2016. Exploring the nature of visual fixations on other pedestrians. Lighting Research \& Technology 50(4):511-521.

Fotios S, Yang B, Uttley J. 2015b. Observing other pedestrians: Investigating the typical distance and duration of fixation. Lighting Research \& Technology 47(5):548-564. 
Gibbons R, Guo F, Medina A, Terry T, Du J, Lutkevich P, Li Q. 2014. Design Criteria for Adaptive Roadway Lighting. McLean, VA: Federal Highway Administration. No. FHWA-HRT-14-051.

Gibbons RB, Meyer J, Terry T, Bhagavathula R, Lewis A, Flanagan M, Connell C. 2015. Evaluation of the Impact of Spectral Power Distribution on Driver Performance. McLean, VA: Federal Highway Administration. No. FHWA-HRT-15-047.

Illuminating Engineering Society of North America. 2000. The IESNA lighting handbook: reference \& application. Illuminating Engineering Society of North America. p. 1004.

Janoff M. 1989. Subjective ratings of visibility and alternative measures of roadway lighting. Journal of the Illuminating Engineering Society 18(1):16-28.

Johnson M, Cook T, Shackleford J, Pang T. 2009. Application Assessment of Bi-Level LED Parking Lot Lighting. Oakland, CA: Pacific Gas \& Electric. No. Report \#0815.

Knight C. 2010. Field surveys of the effect of lamp spectrum on the perception of safety and comfort at night. Lighting Research and Technology 42(3):313-329.

Minoshima O, Oka K, Ikehara K, Inukai N. Research on accident reduction by intersection lighting. Road Engineering Association of Asia and Australia (REAAA); 2006; Manila, Philippines: Road Engineering Association of the Philippines. p. 73-91.

Muttart J, Dinakar S, Suway J, Kuzel M, Maloney T, Biever W, Terpstra T, Voitel T, Cavanaugh D, Harms T. 2017. Comparing A Timed Exposure Methodology to the Nighttime Recognition Responses from SHRP-2 Naturalistic Drivers. WCX ${ }^{\text {TM }}$ 17: SAE World Congress Experience Detroit, MI: SAE Technical Paper. 
Narendran N, Freyssinier J, Zhu Y. 2016. Energy and user acceptability benefits of improved illuminance uniformity in parking lot illumination. Lighting Research \& Technology 48(7):789-809.

Owens DA, Wood JM, Owens JM. 2007. Effects of age and illumination on night driving: a road test. Human Factors 49(6):1115-1131.

Pretto P, Chatziastros A. Changes in optic flow and scene contrast affect the driving speed. Driving Simulation Conference Europe; 2006. p. 263-272.

Rea, Ouellette M. 1991. Relative visual performance: A basis for application. Lighting Research and Technology 23(3):135-144.

Rea MS, Bullough JD, Akashi Y. 2009. Several views of metal halide and high-pressure sodium lighting for outdoor applications. Lighting Research \& Technology 41(4):297-320.

Sullivan GM, Artino Jr AR. 2013. Analyzing and interpreting data from Likert-type scales. Journal of graduate medical education 5(4):541-542.

Terry T. 2011. Comparing LED Lighting Systems in the Detection and Color Recognition of Roadway Objects [Master of Science]. [Blacksburg, VA]: Virginia Tech. p. 118.

Terry TN, Gibbons RB. Road-Surface Contrast and Adaptation of Visibility of Low-Contrast Targets. Transportation Research Board 94th Annual Meeting; 2015; Washington, DC: Transportation Research Board.

Townshend T. 1997. The role of public lighting. Safer City Centres: Reviving the Public Realm. London: Paul Chapman Publishing:119-129. 